\title{
Beyond a Blockchain Paradox: How Intermediaries Can Leverage a Disintermediation Technology
}

\author{
Leonardo Maria De Rossi \\ SDA Bocconi School of Management \\ leonardo.derossi@sdabocconi.it \\ Nico Abbatemarco \\ SDA Bocconi School of Management \\ nico.abbatemarco@sdabocconi.it
}

\author{
Gianluca Salviotti \\ SDA Bocconi School of Management \\ gianluca.salviotti@sdabocconi.it \\ Aakanksha Gaur \\ SDA Bocconi School of Management \\ aasha.gaur@sdabocconi.it
}

\begin{abstract}
New digital technologies are changing the way organizations create and capture value. In particular, blockchain is bringing up opportunities for organizations in terms of transparency and security, and at the same time threatening the position of intermediaries such as banks and notaries. Therefore, intermediaries need to design new business models to generate value from blockchain. Little academic research has been conducted to identify the business models that intermediaries could exploit to leverage a disintermediation technology such as blockchain. Employing a qualitative research based on focus group and interviews, this study highlights how a specific intermediary, the Italian notaries, tried to design appropriate business models to derive value from blockchain ecosystems. Specifically, drawing on the key concepts of value configuration, value creation and business model dimensions, this paper identifies three different business models that Italian notaries can implement to create and capture value from permissionless blockchain ecosystems.
\end{abstract}

\section{Introduction}

By their very nature, disruptive technologies often pose a threat to the pre-existing habits of companies, especially those of large incumbents. Moreover, as the well-known Kodak case demonstrates, it is not enough for a company to be at the forefront in terms of purely technical innovation if the company culture and business models are not innovated as well [31]. Therefore, finding viable solutions to the innovator's dilemma [16] has become over time a fundamental imperative for every company survival.
Digital technologies have further exacerbated this imperative, producing various effects on firms' structures. Data-driven orientation has enabled the transition from a traditional centralized organization to a more distributed and decentralised ecosystem, where companies often act as aggregators of multiple resources for an active group of consumers. For example, internet giants such as Google, Facebook, Uber and AirBnb rely on the contributions of the users to generate value in their platforms. This shift has spearheaded the generation of "dematerialized" organizations, with a changing approach to resources such as physical spaces, assets, or employees [15]. Artificial intelligence breakthroughs are expected to radically transform work practices, with algorithmic intelligence replacing in some cases human intelligence $[19,23,30]$.

More recently, the emergence of distributed trust systems such as those based on blockchain has challenged the view of organizations as a central source of legitimacy $[50,51]$ leading to the creation of P2P transaction systems that do not require validation by trusted third parties. The most recent wave of blockchain technologies seem to be particularly threatening the existing business models and advantageous positions of traditional institutions such as governments, banks and notaries [9, 47]. For example, blockchain based applications (eg. smart contracts) could dissolve intermediaries like clearing departments and notaries [35].

Of all the incumbents, intermediaries have been among the most negatively impacted by the introduction of digital technologies. For example, in the last 20 years, travel agents have been heavily impacted by the advent of Internet. The latest evidences from Labor's Occupational Outlook Handbook, predicted a $12 \%$ decline in employment over the decade from 2016 to 2026. Travel agencies suffered the rise of independent travelling and are 
trying to embrace the online and mobile channels in order to stay competitive [33, 55]. However, technologies can support intermediaries as well. Investment advisors should have been totally disrupted by robo-advisors - a cheaper, more accessible, transparent and unbiased financial service [53]. Yet, robo-advisors have failed to capture significant market shares, and still appear to be more of a niche solution than a mainstream competitor to traditional financial advisory companies. This failure does not mean that this technology will not impact the financial sector; estimates are that hybrid services, such as financial advisors supported by robo-advisors, will gain the upper hand in the financial market [26, 27]. Thus, established intermediaries are deeply incentivized in finding solutions that will allow them to innovate their business models and better position themselves in terms of value propositions.

To sum up our argument, digital technologies such as big data, IoT and blockchain are radically changing the way economic activities are organized and coordinated within ecosystems. Traditional institutions and more importantly intermediaries need to embrace the rapid advances in the digitization of activities and processes and to reshape their existing business models to create and capture value from these new sources.

With this paper, we seek to contribute to the emerging research on how blockchain-enabled ecosystems can contribute to create new business models or enhance existing ones. In particular, our study is aimed at understanding how organizations such as intermediaries, theoretically threatened by this technology, can instead extract value from it. In particular, we undertook a study on a specific set of intermediary organizations, the Italian notaries, and explored how they could leverage blockchain-enabled ecosystems to design new business models or improve the range of services they already offer.

Key concepts we build upon for our analysis include value creation [5], business models [2, 24, 48] and value configuration [28, 54]. We elucidate these concepts in Section 2, together with a brief overview of blockchain technology. In Section 3, we provide a description of our empirical case and reasons for selecting it, as well as a summary of our data collection and analysis. After presenting our empirical results in Section 4, we conclude by highlighting the insights generated, discussing our contributions and their implications in Section 5.

\section{Literature review}

The adoption of digital technologies has the potential to transform key business operations, products and processes, and to shape organizational structures and value chains [34]. When implementing digital technologies into their legacy systems, firms face the issue of how to reshape existing business models and create new ones that facilitate the integration with the ecosystems gravitating around them, thus allowing for value creation and capture. In the following sub-paragraphs, we elucidate the most relevant approaches provided by the existing literature on the topics of value creation and capture, with particular reference to the notion of value configuration [54] and the V4BM framework proposed by Al-Debei \& Avison [2]. Finally, we also provide a brief explanation of what blockchain technology is, including a description of some of its most important features.

\subsection{Value configuration and value creation}

A business model "describes the rationale of how an organization creates, delivers and captures value" [41]. Many scholars from information systems and management literature have explored the concepts of value configuration logic and value creation in business models [5, 24, 42, 44].

For example, Stabell \& Fjeldstad [54] highlighted the notion of value configuration and identified three configurations through which organizations provide value: value chain, value shop, and value network. Each of the three forms differs in terms of value proposition: for example, in the value chain configuration value is generated by transforming inputs into valuable outputs. Firms operating the value network model, instead, provide value primarily by linking and matching different stakeholders. Finally, in the value shop configuration, value is provided by evaluating customers' problems and revising them iteratively until they are solved [28]. In a similar manner, Pagani [44] argue that digital businesses create value by bringing together two or more distinct groups of customers and creating an infrastructure that substantially reduces the transaction costs among them.

As for value creation, Bowman \& Ambrosini [13] define it as the contribution to the utility of the final good or service to end users and distinguish it from value capture defined as the difference between revenue and cost retained by the firm. Building upon a multiple case study of 59 American and European ebusinesses, Zott \& Amit [61] identify four sources of value creation: efficiency, complementarities, lock-in, and novelty. More precisely, Zott \& Amit [61] refer to:

- Novelty - as the level of uniqueness of goods or services offered by a business; it represents a new way of satisfying existing market needs or finding and addressing entirely new needs; 
- Lock-in - as the total costs which a customer should sustain to move to another vendor. It is assumed that the higher the switching costs the tighter the customer lock-in;

- Complementarities - as the total benefits provided by being able to dispose of a bundle of goods together rather than having each of the goods separately;

- Efficiency - as the general benefits provided to customers in terms of time, effort, costs.

These four sources of value creation are also applicable to digital businesses [4].

\subsection{Business model dimensions}

The V4BM framework proposed by Al-Debei \& Avison [2] represents a comprehensive framework that identifies four key value dimensions. They are value proposition, value stakeholder ecosystem, value finance and value architecture.

- Value proposition: This dimension includes descriptions of the core services and products that the organization offers along with their intended value elements [2, 32]. Moreover, Amit \& Zott [6] have highlighted that from a firm-based point of view the evaluation of a value proposition should explicitly include all the stakeholders, rather than only the customers;

- Value stakeholder ecosystem: This dimension is representative of the external arrangements and relationships that an organization entertains with its stakeholders [2]. Such stakeholders include a large array of actors such as suppliers, customers, marketers and competitors [13, 20, 24]. Thus, this dimension depicts the inter-organizational value perspective [3];

- Value finance: This dimension is useful to illustrate the cost structure and revenue streams for the organization. This dimension defines how the firms captures the value it creates [42, 43];

- Value architecture: This dimension focuses on the structural design of a company, including its technological architecture and organizational infrastructure. It comprises a series of assets, resources (tangible and intangible), and core competencies. In this context, Hedman \& Kalling [24] indicate that to serve the market, any organization needs resources that could take human, physical, and technological forms.

\subsection{Blockchain technology and its features}

A blockchain is a decentralized database structured in blocks, each one containing a certain amount of information and distributed through a chain (i.e. a ledger) over a network. Hence, it is a digital way to store any kind of data, be it a token of value or a crypto money balance, through a network (for example, the Internet).

Data stored in a blockchain cannot be lost. They are there forever, replicated as many times as the number of nodes in the network. Nodes add new data to the blockchain after reaching an agreement among them. Therefore, if correctly implemented, blockchain technology can guarantee security, immutability, and transparency of data [49].

In terms of governance, a blockchain can be divide in two macro-categories: permissioned and permissionless, referring to the possibility for a node to take part in the consensus mechanism freely or not [17]. More specifically, in permissionless blockchains anyone, including malicious actors, can participate in the consensus process, while permissioned blockchains are kept centralized to one - or more - authorized user.

\section{Research context and methodology}

\subsection{Context: the Italian notary system}

Within the Italian scenario and more generally in civil law countries, the notary plays a crucial role dealing with many different tasks. In particular, the notary is a public official established to receive and certify acts occurring inter vivos (i.e. sales, exchanges, divisions, mortgages, etc.) and acts of last will (i.e. testaments), give them the necessary publicity for validity or enforceability with third parties, and keep and issue their copies, summaries and extracts. A deed redacted by the notary is a public act, that has a particular legal status: what the notary attests in the deed (e.g. that he read its content in front of the parties and received their approval, or that a person has made or signed a declaration in front of him) is "fully proofed" (i.e. must be considered true by a judge unless the crime of forgery is ascertained).

The peculiar characteristics of a notary are two:

- The trustworthiness, which rests on his impartiality, on a high-level legal and fiscal preparation, and on his nature as a public official (guarantor of the truthfulness and legality of the acts);

- The reliability, consisting in the fact that the notary exercises his function not as an employee of the State, but within a free professional organization that guarantees efficiency.

Given the intrinsic characteristics of transparency, immutability and security of a blockchain system [45, $46,56,60]$ the similarities between this technology and the role of the notary have been already highlighted by 
numerous studies, together with the idea of transforming the blockchain into a sort of virtual notary able to certify the correctness of certain documents (e.g. land properties sale) [8, 22].

However, to date there are at least two substantial constraints on the adoption of blockchain as an autonomous notarization system. First, the still inadequate technological level of biometric recognition systems prevents the creation of failsafe systems for representing a physical asset in a digital format: " $a$ blockchain is only as reliable as those responsible for establishing the link between the asset and what refers to it on the blockchain" [7]. Second, there is still no system of governance for blockchain that can accurately determine who is legally responsible for the information shared in a decentralized and distributed ecosystem.

Our hypothesis is that the notary can fill in these gaps in his role of public officer, bound by legal obligations and fully accountable for the truthfulness and correctness of the documents he certifies. Therefore, we investigate the possibility of using blockchain as a tool capable of supporting and improving notarization work and enabling new business models to expand the portfolio of services offered by a notary.

\subsection{Methodology}

In order to address our hypothesis, we adopted a qualitative exploratory study based on nominal group technique, focus groups and interviews [37, 52, 57, 58]. Focus group is a method of collecting qualitative data from multiple individuals through informal discussions focused on a specific topic [29, 38].

The study took place in three phases. In Phase 1 , a series of 3 internal sessions, each one 2 hours long, was held over a period of 7 months in order to broadly define the scope of the research. The participants in such meetings included 6 notaries belonging to the Italian Council of Notaries, the President and the CIO of Notartel - the company providing ICT services for Italian notaries - and 5 blockchain and IS experts from the academia, 2 of which acting as facilitators during the discussions. The brainstorming sessions were organized according to classical steps of the nominal group technique [57, 58]: in the first session, after introducing the existing scientific literature and the actual implementation possibilities, each participant was required to write down ideas on feasible use cases and then sharing them with the other participants. Six concepts, summarized in Table 1, emerged during this first meeting. In the second session, the ideas previously generated were discussed and furtherly clarified to all the participants. Finally, in the third session each of the participant ranked the ideas from one (lowest) to six (highest). Only the three ideas with the higher average ranking were selected for further analyses.

Table 1. Debated use cases

\begin{tabular}{|l|l|}
\hline Use case & Ranking \\
\hline Multisig services for cryptocurrencies & 4.81 \\
\hline Digital identity mgmt. in blockchain & 4.45 \\
\hline Escrow services for smart contracts & 3.63 \\
\hline Tracking platform for luxury goods & 3.09 \\
\hline Forensic analysis on crypto funds & 2.54 \\
\hline Physical asset tokenization & 2.45 \\
\hline
\end{tabular}

The first use case selected was management of multisig services for cryptocurrencies [1, 59]. One of the fundamental characteristics of a permissionless blockchain is the security guaranteed to its users and obtained thanks to the decentralization and distribution of the network that maintains it. At the same time, however, there have been numerous cases of theft, loss or non-voluntary transfer of cryptocurrencies or other crypto-assets. On the one hand, a public blockchain is a secure architecture from an IT point of view. On the other hand, however, the ecosystems of services built around it are not the same - especially with regards to the software used for saving/transferring cryptocurrencies (called "wallet") and the platforms needed to buy and sell them ("exchanges"). A solution to solve this issue problem could be a multi-key service (more commonly "multisig"), wherein both the final user and a third party must sign a transaction in order for it to be valid.

A second use case was association of digital identities in the blockchain world, which relates to the provision and management of reliable digital identity systems $[10,36]$. The traditional identification systems (e.g., identity card, driving license and passports) are used in a circumstantial manner within a reference community, in which the issuing authority guarantees the truthfulness of the data entered. However, in a trustless and open environment like the Internet, there is no comparable entity. Blockchain technology introduces a further element of uncertainty to the whole scenario. In fact, the system of public/private keys at the base of the same guarantees a high level of anonymity, being the identity of the user represented only to an alphanumeric code. Although anonymity in some cases is a necessary aspect, it is conceivable that in practice it has slowed down the adoption of technology so far, being in total opposition to the stringent anti-money laundering (AML) and know-your-consumer (KYC) procedures recently adopted. 
The third use case identified was the delivery of escrow services for public smart contracts [18, 39]. Within a smart contract, all the necessary conditions are set to make a transfer of a token happen. Clearly, the transfer conditions may be the most disparate and depend strictly on the type of smart contract in question. However, the physical world is still today very difficult to represent in the digital world. What is missing is a system of escrow (guarantee) that ensures that a physical asset is represented in a confirmatory manner in the digital world, in order to enable the exchange on blockchain platforms.

Following the identification of the use cases, in Phase 2 a focus group session was organized at a leading Italian business school with thirty-two participants from consulting organizations, blockchain based start-ups, and digital transformation firms. A brief summary of the participants' profile and experience is depicted in Tables 2, 3 and 4.

Table 2. Profile of the respondents

\begin{tabular}{|l|l|}
\hline Respondents' profile & N. of participants \\
\hline Consultant \& analyst & 10 \\
\hline Head of business development & 2 \\
\hline Blockchain developer & 5 \\
\hline Project \& product manager & 8 \\
\hline Sales manager & 3 \\
\hline CTO \& IT architect & 4 \\
\hline
\end{tabular}

Table 3. Focus 1 - Working experience

\begin{tabular}{|l|l|}
\hline Working experience & N. of participants \\
\hline 1 year or less & 4 \\
\hline $2-5$ & 16 \\
\hline $5-9$ & 5 \\
\hline $10+$ & 7 \\
\hline
\end{tabular}

Table 4. Focus 2: Blockchain experience

\begin{tabular}{|l|l|}
\hline Experience with blockchain & N. of participants \\
\hline 1 year or less & 17 \\
\hline 2 & 9 \\
\hline 3 & 2 \\
\hline 4 & 1 \\
\hline $5+$ & 3 \\
\hline
\end{tabular}

In this phase, an introductory explanation session was first held in order to make it easier for the participants to understand the three models under study. Therefore, the participants were organized into three groups to collect their thoughts about the key question of "How intermediaries can create value and complement their existing services by leveraging permissionless blockchain?".

The respondents were distributed proportionally in the various groups according to their years of experience with blockchain and their working backgrounds. Furthermore, each group was moderated by a blockchain expert from the academia plus a member of the Italian Council of Notaries.

Each of the groups was asked to choose one of the three use cases preselected during Phase 1 and translate the general idea into a well-defined business model, focusing in particular on the following unstructured points:

- The trustworthiness, which rests on his impartiality (all parts of the contract are protected), on a highlevel legal and fiscal preparation, and on his nature as a public official (guarantor of the truthfulness and legality of the acts);

- Main actors of the solution;

- Plausible revenues/costs structure;

- Technological architecture;

- Main pros and cons;

- Legal and accountability issues.

The data obtained in this phase were collected both in text and video formats.

Finally, in Phase 3, a follow-up online questionnaire was distributed to the participants to summarize the previous results and collect additional information on the solutions that emerged from the brainstorming session. In the survey, after providing a brief description of their solution, the participants in the focus groups answered to the following semistructured questions:

- What is the role of the notary in the solution?

- Are there any inconsistencies with the current notary business models?

- What are the valuable aspects of the solution for the notaries?

- What are the valuable aspects of the solution for the customers?

- Who are the other stakeholders involved in the solution?

- Does the solution provide valuable social benefits?

- On which technological platforms may the solution be developed?

- How much would the current scalability of blockchain technology limit the solution?

- What are costs and revenues of the solution?

- Does the solution include one or more persons responsible for the initiative?

- How much would the existing legislative gaps limit the solution?

The questions posed to the respondents were used to identify stakeholders for the service, the valuable aspects for notaries, the benefits accrued to the stakeholders, the revenues streams and costs structures, 
the governance mechanisms, and the technical protocols involved.

\section{Findings}

The analysis led us to some interesting findings. The value creation model originally proposed by Amid $\&$ Zott [5] is an appropriate lens to explore the case of Italian Notaries with blockchain. According to the authors, there are four sources of value creation for businesses: (i) novelty, (ii) lock-in, (iii) complementarities, and (iv) efficiency. The Italian Notaries could create value from the proposed solutions exploiting these four sources.

The first use case - multisig services for cryptocurrencies - would represent a new form of business model for notaries (novelty) and a possible solution to increase cryptocurrencies' security [12]. Moreover, it could provide actual benefits to all the cryptocurrencies' holders that currently want to store and transfer crypto assets in a much more secure way (efficiency). Finally, this solution could enable other cross-services, such as automatic transfer of cryptocurrencies in case of will execution (complementarities). According to Article 603 of the Italian Civil Code, Italy requires a citizen to have a notary sign his will to be valid for all legal purposes. This means that if a crypto holder wants to create a self-made will for his own crypto-assets, he will need a notary to confirm the authenticity of the will. Thus, notaries could be the only entities having the legal power to split crypto-assets among different heirs in case of death (lock-in).

The second use case - association of digital identities in the blockchain world - would represent a way of consolidating their role of certification authorities within the Italian ecosystem. The notaries would be a core actor within the Italian blockchain ecosystem (lock-in) becoming the entity authorized by law to identify cryptocurrencies' holders (novelty).

Finally, the third use case - escrow services for public smart contracts - would represent both a new service (novelty) and a complementary offer, considering that the notary already provides a service of certification of high-value physical goods (complementarities).

In the following subsections, we describe each business model in detail, explaining their value configurations and business model dimensions.

\subsection{Business Model 1 - Notary as Custodian}

4.1.1 Digital business model. In this case, the task of the notary consists in managing cryptocurrencies' wallets together with the clients. More specifically, the notary will manage a multi-signature key to authorize transactions happening on one or more of the customer's wallets.

4.1.2 Value configuration. The custodian model is configured as a value shop, as it is the solution to a specific cryptocurrencies' problem related to security and recovery.

\subsubsection{Value dimensions.}

- Value proposition: In the custodian model, the custody of keys represents the main additional security service, allowing cryptocurrencies' holders to be protected from frauds, thieves or hackers. Moreover, in case of death, cryptocurrencies would not be lost but split between the different heirs following the customer's will instructions. As stated by one of the participants, "this is the perfect technological solution to avoid the loss of blockchain keys - and thus the consequent permanent loss of all the cryptocurrencies owned".

- Value stakeholder ecosystem: A diffusion of this service could benefit the entire Italian network of cryptocurrencies' holders interested in higher level of security. Furthermore, the introduction of multisignature services could lead to a legal (and technical) way of transferring the property of cryptocurrencies after a person's death, guaranteeing to all crypto-holders a possibility to legally transfer their assets to their heirs.

- Value architecture: The service would be offered through an integrated platform to manage the multisignature service by the National Council of Notaries. As stated by one participant "the solution will be composed by a multi-signature wallet and a key repository system".

- Value finance: On one side, notaries would need to sustain an initial cost related to the implementation of the multi-signature wallet and a creation of a highly-secure key repository system. Furthermore, it would be required to organize some advanced training sessions to teach notaries how to use this new solution. On the other side, notaries would receive revenues in form of a commission for each managed key.

\subsection{Business Model 2 - Notary as ID Authenticator}

4.2.1 Digital business model. In this case, the task of the notary consists in creating an authenticated system of certification of blockchain addresses. This allows to extend to the field of cryptocurrencies the previous 
business model of the notary, which is already authorized by law to identify its customers in relation to the AML/KYC guidelines.

4.2.2 Value configuration. The authenticator model is configured as a value network, given the key role of the notary in enabling the creation of an authenticated ecosystem of final users adopting cryptocurrencies.

\subsubsection{Value dimensions.}

- Value proposition: In the authenticator value configuration, the certification issued by the notary acts as proof of ownership, allowing the construction of a network of cryptocurrencies users that assures security and privacy (guaranteed by the notary's trustworthiness) without renouncing to compliance with the principles of accountability and the stringent anti money laundering (AML)/know your customer (KYC) compliance procedures. As stated by one of the participants, "it is possible that this solution will increase the acceptance of the blockchain as technology by the mainstream public", also pushing for the recognition of cryptocurrencies as legal tender money.

- Value stakeholder ecosystem: A major acceptance of cryptocurrencies could in turn benefit other stakeholders, such as new businesses that decide to accept cryptocurrency as a means of payment. Other important stakeholders would be i) the public administration, facilitated in the creation of a fiscal framework related to cryptocurrencies, and ii) banks interested in implementing cross-selling services.

- Value architecture: The service would be provided by notaries through a partially expanded architecture compared to the one already existing today to ascertain the identity of their customers. An interviewed participant affirmed this "the solution is based on the reutilization of the existing infrastructure already used by the notaries, as only minimum investments would be necessary to extend its functionalities in order to interact with a permissionless blockchain”. At the organizational level, management and responsibility of the architecture would fall into the notaries' hands.

- Value finance: In terms of economic sustainability, the notaries will sustain an initial cost related to the upgrade of the technological architecture and the training necessary to learn how to use it. Revenues, on the other side, will be generated by the payment of a variable fee by the customer at each address registration and this will depend on the process of due diligence. As one participant highlighted, "the cost of due diligence related to the registration of a user addresses will vary from case to case".

\subsection{Business Model 3 - Notary as Validation Oracle}

4.3.1 Digital business model. In this case, the task of the notary consists in being a validation oracle, similar to the one identified by Notheisen et al. [39], i.e. in certifying that the exchange of token representing a physical asset produces legal binding effects. This represent a completely new business model for a notary, albeit taking up the role already performed of authorised certifier of high-value goods.

4.3.2 Value configuration. The validation oracle model is configured as a value chain, as it is inserted within the life cycle of a product allowing its dematerialization and representation as a certified virtual token.

\subsubsection{Value dimensions.}

- Value proposition: The role of the notary as a validation oracle allows the dematerialization of a physical asset and its representation as a virtual token, while keeping the certainty that the good is precisely identified and that the subsequent exchanges of the token occur produce legally binding effects.

- Value stakeholder ecosystem: The tokenization of an asset allows the creation of a transparent and immutable record available to all the stakeholders interested in the "traceability of real rights on the assets in question". Furthermore, tokenization could lead to at least two other interesting outcomes: an increase of liquidity in illiquid markets and an the "opening of niche markets to small-to-mid savers". An example is that of great artworks, which could be sold in terms of digital micro-shares, although not obviously compromising their physical nature.

- Value architecture: The service would be offered through an integrated platform by the National Council of Notaries. Therefore, the notaries will be responsible for the management and accountability of such solution, even though other auditing roles could be considered for other entities, such as "the public administration that could check the compliance of tokens to the KYC/AML compliance procedures".

- Value finance: The notaries could charge a margin for each asset certified and then apply a fixed fee to authorize each transaction. As one participant elaborated, "the notaries will apply a margin when 
certifying the ownership of the real rights on assets and later charge a fixed fee to confirm each subsequent token exchange". As for costs, the greater would be linked to the implementation of the platform through which it will be possible to offer the service.

\section{Conclusions}

According to the results emerging from the focus group, there are many ways in which an intermediary can use an innovative technology like blockchain to consolidate its position rather than see its own role jeopardized by it.

As already described by Iansiti \& Lakhani [25], blockchain technology seems to be characterized by a foundational, more than disruptive, nature. This nature implies that in the construction of a blockchain ecosystem, more entities may be involved to ensure its correct operativity.

Notaries can crucially contribute to the development of such an ecosystem. Despite some similar characteristics, today a blockchain protocol is far from being a perfect substitute of a notarization system. On the opposite, notaries can contribute in solving some of the most important problems that have limited the development and diffusion of this technology to date, complementing its main characteristics (immutability, transparency and security) with their own (trustworthiness and efficiency).

In particular, the study highlighted how notaries can become part of a blockchain ecosystem in at least three different value configurations [54]:

- as Custodian of crypto-assets, enabled to authorize transfers on behalf of their legitimate owner. This solution aims to solve limitations inherent to safety - intended as security in accessing and managing the crypto-assets - thus answering one of the most relevant issue for crypto-holders today (value shop) and potentially leading to the introduction of new cross-services, such as the smart heritage;

- as a Digital ID Authenticator, qualified to certify the legal origin of crypto-assets and the identity of their owners. This solution would allow the creation of a network of certified crypto-assets users, leading to the resolution of the critical issues related to the fulfilment of the AML/KYC procedures, to the creation of ancillary services related to crypto-assets and to a greater recognition of crypto-assets at a regulatory and systemic level (value network);

- as a Validation Oracle, able to validate transactions of tokenized goods that have a physical underlying asset. This solution would allow notaries to become part of the value chain of products that today cannot be "dematerialized", due to the difficulty in certifying that the owner of the digital copy is entitled to the full enjoyment of the rights guaranteed by the possession of the physical asset (value chain).

On the other hand, such value configuration would bring advantages to the notaries themselves. Through the three use cases, notaries would have the opportunity to develop new business models and innovate their existing ones by adding value in terms of:

- Novelty: through the proposition of new services to a new customer niche (no risk of cannibalization of the current customers);

- Lock-in: positioning themselves as the only entity able to offer such services with a high level of efficiency but also maintaining the confidentiality and privacy of their customers;

- Complementarity: due to the possibility of offering cross-services compared to the current ones;

- Efficiency: providing the most reliable option to guarantee the safety of owned crypto-assets.

Following these results, it appears that intermediaries such as the notaries might eventually consolidate their position by creating value and capturing it through the business models identified above. Our findings respond to the call by Risius \& Spohrer [47] to identify whether blockchain applications can replace or consolidate intermediary services providers' business. We respond to this call by highlighting that intermediaries might not be disintermediated as many think, and rather they could strengthen their business by implementing different business models such as the three identified in this study. These new business models will enable them to enlarge their customer base, lock-in it, and create new and complementary services.

From our study, it emerges that the implementation of a new technology such as the blockchain does not guarantee automatically the transition to a more disintermediated and decentralized ecosystem of services. On the contrary, depending on the foundations upon which the technology is built, it can even lead to the consolidation and the expansion of the role of intermediaries.

\subsection{Limitations and further research}

The contribution of this study should be evaluated in light of some limitations, which also provide 
directions for future research in this area. First, the generalizability of our study is limited to the peculiar notary context in Italy and more generally in civil law countries. Although our research focuses on the business models that notaries could exploit, a robust recognized legislation offering a framework for the classification of crypto-assets is yet to be established. Therefore, future research could be aimed at analysing the feasibility of the business models presented in this paper at the legal level, also in different jurisdictions, in order to better understand the profiles of responsibility and the compliance requirements linked to the various solutions.

Moreover, we would also like to point out the practical issues related to the implementation of the identified business models. While we have identified potential business models to apply on today's ecosystems, these elements are not definitive; business models and ecosystems require in fact a periodic reassessment as they evolve over time, especially when the future development of their underlying technology is so uncertain [40].

\section{References}

[1] Aitzhan, N. Z., \& Svetinovic, D. (2018). Security and privacy in decentralized energy trading through multisignatures, blockchain and anonymous messaging streams. IEEE Transactions on Dependable and Secure Computing.

[2] Al-Debei, M. M., \& Avison, D. (2010). Developing a unified framework of the business model concept. European Journal of Information Systems.

[3] Al-Debei, M. M., \& Al-Lozi, E. (2014). Explaining and predicting the adoption intention of mobile data services: A value-based approach. Computers in Human Behavior.

[4] Amit, R., \& Han, X. (2017). Value creation through novel resource configurations in a digitally enabled world. Strategic Entrepreneurship Journal, 11(3), 228-242.

[5] Amit, R., \& Zott, C. (2001). Value creation in E-business. Strategic Management Journal, 22(6-7).

[6] Amit, R., \& Zott, C. (2015). Crafting business architecture: The antecedents of business model design. Strategic Entrepreneurship Journal, 9(4), 331-350.

[7] Ammous, S. (2016). Blockchain Technology: What is it good for Retrieved from https://papers.ssrn.com/sol3/papers.cfm?abstract_id=283275 1

[8] Anand, A., McKibbin, M., \& Pichel, F. (2016). Colored coins: Bitcoin, blockchain, and land administration. In Annual World Bank Conference on Land and Poverty.

[9] Atzori, M. (2015). Blockchain technology and decentralized governance: Is the state still necessary?.

[10] Avital M, Beck R, King J, Rossi M, Teigland R (2016). Jumping on the blockchain bandwagon: lessons of the past and outlook to the future. In: Proceedings of the 37th International conference on information systems.

[11] Beck, R., Avital, M., Rossi, M., \& Thatcher, J. B. (2017). Blockchain Technology in Business and Information Systems Research. Business \& Information Systems Engineering, 59(6), 381-384.

[12] Bonneau, J., Miller, A., Clark, J., Narayanan, A., Kroll, J. A., \& Felten, E. W. (2015, May). Sok: Research perspectives and challenges for bitcoin and cryptocurrencies. In Security and Privacy (SP), 2015 IEEE Symposium on (pp. 104-121).

[13] Bowman, C., \& Ambrosini, V. (2000). Value creation versus value capture: towards a coherent definition of value in strategy. British journal of management, 11(1), 1-15.

[14] Bouwman, H. (2002). The sense and nonsense of Business Models. In International Workshop on Business Models, HEC Lausanne.

[15] Catalini, C. (2017). How blockchain Technology Will Impact the Digital Economy. Oxford Law Faculty Blog.

[16] Christiansen, C. (1997). The innovator's dilemma. Harvard Business School Press, Boston.

[17] De Rossi, L. M., Abbatemarco, N., \& Salviotti, G. (2019, January). Towards a Comprehensive Blockchain Architecture Continuum. In Proceedings of the 52nd Hawaii International Conference on System Sciences.

[18] Egelund-Müller, B., Elsman, M., Henglein, F., \& Ross, O. (2017). Automated Execution of Financial Contracts on Blockchains. Business \& Information Systems Engineering, 59(6), 457-467.

[19] Galliers, R. D., Newell, S., Shanks, G., \& Topi, H. (2017). Datification and its human, organizational and societal effects. The Journal of Strategic Information Systems, 26(3), 185-190.

[20] Giaglis, G. M., Kallio, J., Tinnilä, M., \& Tseng, A. (2006). An international comparison of operator-driven business models. Business Process Management Journal.

[21] Gillon, K., Aral, S., Lin, C.-Y., Mithas, S., \& Zozulia, M. (2014). Business Analytics: Radical Shift or Incremental Change? Communications of the Association for Information Systems, 34.

[22] Graglia, J. M., \& Mellon, C. (2018). Blockchain and Property in 2018: At the End of the Beginning. Innovations: Technology, Governance, Globalization.

[23] Günther, W. A., Rezazade Mehrizi, M. H., Huysman, M., \& Feldberg, F. (2017). Debating big data: A literature review on realizing value from big data. Journal of Strategic Information Systems, 26(3), 191-209.

[24] Hedman, J., \& Kalling, T. (2003). The business model concept: theoretical underpinnings and empirical illustrations. European Journal of Information Systems.

[25] Iansiti, M., \& Lakhani, K. R. (2017). The truth about blockchain. Harvard Business Review, 95(1), 118-127.

[26] Jung, D., Dorner, V., Glaser, F., \& Morana, S. (2018). Robo-Advisory. Business \& Information Systems Engineering, 60(1), 81-86. 
[27] Kaya, O., Schildbach, J., AG, D. B., \& Schneider, S. (2017). Robo-advice-a true innovation in asset mgmt.

[28] Kazan, E., Tan, C.-W., \& Lim, E. T. K. (2015). Value Creation in Cryptocurrency Networks: Towards A Taxonomy of Digital Business Models for Bitcoin Companies. In PACIS (p. 34).

[29] Krueger, R. A., \& Casey, J. (2009). Successful focus groups: practical guidelines for research. Thousand Oaks.

[30] Loebbecke, C., \& Picot, A. (2015). Reflections on societal and business model transformation arising from digitization and big data analytics: A research agenda. The Journal of Strategic Information Systems, 24(3), 149-157.

[31] Lucas Jr, H. C., \& Goh, J. M. (2009). Disruptive technology: How Kodak missed the digital photography revolution. The Journal of Strategic Information Systems,.

[32] Magretta, J. (2002). Why business models matter. Harvard Business Review, 80(5), 86.

[33] Martini, U. (2000, October). L'impatto di Internet sulla struttura del mercato turistico leisure. In abstract del workshop "Turismo e internet: una relazione possibile".

[34] Matt, C., Hess, T., \& Benlian, A. (2015). Digital transformation strategies. Business \& Information Systems Engineering, 57(5), 339-343.

[35] Möhring, M., Keller, B., Schmidt, R., Rippin, A. L., Schulz, J., \& Brückner, K. (2018). Empirical Insights in the current development of smart contracts. In Proceedings of the 22nd Pacific Asia Conference on Information Systems.

[36] Moyano, J. P., \& Ross, O. (2017). KYC optimization using distributed ledger technology. Business \& Information Systems Engineering, 59(6), 411-423.

[37] Myers, M., \& Newman, M. (2007). The qualitative interview in IS research: Examining the craft," Information and Organization [Online].

[38] Nili, A., Tate, M., \& Johnstone, D. (2017). A framework and approach for analysis of focus group data in information systems research. Communications of the Association for Information Systems, 40(Article 1), 1-21.

[39] Notheisen, B., Cholewa, J. B., \& Shanmugam, A. P. (2017). Trading Real-World Assets on Blockchain. Business \& Information Systems Engineering.

[40] Ojala, A. (2016). Business models and opportunity creation: How IT entrepreneurs create and develop business models under uncertainty. Information Systems Journal.

[41] Osterwalder, A., \& Pigneur, Y. (2010). Business model generation: a handbook for visionaries, game changers, and challengers. John Wiley \& Sons.

[42] Osterwalder, A., Pigneur, Y., \& Tucci, C. L. (2005). Clarifying business models: Origins, present, and future of the concept. Communications of the Association for Information Systems, 16(1), 1-40.

[43] Ovans, A. (2015). What is a business model. Retrieved from https://hbr.org/2015/01/what-is-a-business-model

[44] Pagani, M. (2013). Digital business strategy and value creation: Framing the dynamic cycle of control points. Mis Quarterly, 37(2), 617-632.
[45] Pilkington, M. (2016). 11 Blockchain technology: principles and applications. Research handbook on digital transformations, 225.

[46] Puthal, D., Malik, N., Mohanty, S. P., Kougianos, E., \& Yang, C. (2018). The blockchain as a decentralized security framework. IEEE Consum. Electron. Mag.

[47] Risius, M., \& Spohrer, K. (2017). A Blockchain Research Framework. Business \& Information Systems Engineering, 59(6), 385-409.

[48] Saebi, T., \& Foss, N. J. (2015). Business models for open innovation: Matching heterogeneous open innovation strategies with business model dimensions. European Management Journal, 33(3), 201-213.

[49] Salviotti, G., De Rossi, L. M., \& Abbatemarco, N. (2018, January). A structured framework to assess the business application landscape of blockchain technologies. In Proceedings of the 51st Hawaii International Conference on System Sciences.

[50] Seidel, M.-D. L. (2018). Questioning Centralized Organizations in a Time of Distributed Trust. Journal of Management Inquiry, 27(1), 40-44.

[51] Seidel, M.-D. L., \& Greve, H. R. (2017). Emergence: How Novelty, Growth, and Formation Shape Organizations and Their Ecosystems (pp. 1-27).

[52] Slavova, M., \& Karanasios, S. (2018). When Institutional Logics Meet Information and Communication Technologies. Journal of the Association for Information Systems, 19, 775-812.

[53] Singh, I., \& Kaur, N. (2017). Wealth Management Through Robo Advisory. International Journal of ResearchGranthaalayah, 5(6).

[54] Stabell, C. B., \& Fjeldstad, Ø. D. (1998). Configuring value for competitive advantage: on chains, shops, and networks. Strategic Management Journal, 19(5), 413-437.

[55] Tse, A. C. B. (2003). Disintermediation of travel agents in the hotel industry. International Journal of Hospitality Management, 22(4), 453-460.

[56] Underwood, S. (2016). Blockchain beyond bitcoin. Communications of the ACM, 59(11), 15-17.

[57] Van De Ven, A., \& Delbecq, A. L. (1971). Nominal versus interacting group processes for committee decisionmaking effectiveness. Academy of Management Journal.

[58] Van de Ven, A., \& Delbecq, A. L. (1974). The effectiveness of nominal, Delphi, and interacting group decision making processes. Academy of management Journal, 17(4), 605-621.

[59] Yang, D., Kou, L., \& Liu, A. (2017). U.S. Patent No. $9,672,499$. U.S. Patent and Trademark Office.

[60] Zheng, Z., Xie, S., Dai, H., Chen, X., \& Wang, H. (2017, June). An overview of blockchain technology: Architecture, consensus, and future trends. In 2017 IEEE International Congress on Big Data.

[61] Zott, C., \& Amit, R. (2010). Business model design: an activity system perspective. Long Range Planning. 